interests, researchers and the institutions they serve. Most are condemned to death and even the survivors are treated as objects without moral value.

One last word. If the subject is not to be exploited, even benevolent action intended to promote its welfare presents a moral issue. Can it be imposed without being invasive? The "informed consent" that only recently has been required for experimentation on human subjects is obviously out of the question for nonhuman animals. It is, therefore, imperative that their interests be represented, however imperfectly, by human advocates. I should like to believe that some of those advocates who will lend their voice to speak on behalf of the animals will be found among our students. Why should they not include students of biology-the science that studies and that should respect--if not revere-life?

\section{Star-Nosed Mole}

To live beneath the earth

Is to change. You must learn

To swim without water.

Your bones become coral.

Your hands grow wide as

Paddles, and your nails

Sharpen into the cutlery

That can dig you through.

Nothing can wave you back.

You are the maker of bridges.

You bridge the sky and the earth.

You let the air to tunnel down,

The noon sun to spill into

The darkness that blinds you.

All day beneath the roots,

You must dance, beneath

The burrowing beetle

Where the fallen bird has gone to fly, You, its only star.

Kathryn Winograd

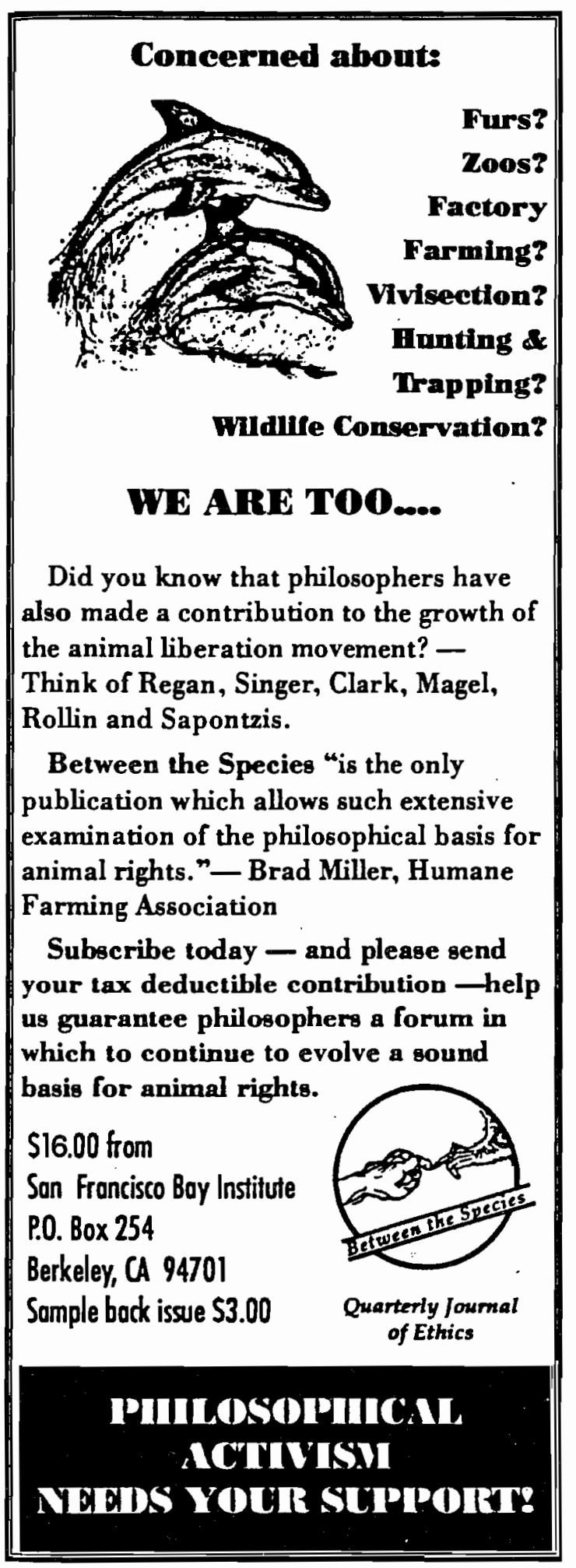

